\title{
DIFFERENCES IN CONFLICT MANAGEMENT BASED ON GENDER AND PERSONALITY TYPE
}

\author{
Peter M. Ostafichuk, Navid Shirzad, Agnes d'Entremont, Stephen Mattucci, and Carol Naylor \\ University of British Columbia \\ ostafichuk@mech.ubc.ca
}

\begin{abstract}
This study examines factors influencing student conflict management styles in a team-based second year mechanical engineering design course. Maddux described conflict management along the dimensions of assertiveness (seeking to meet one's own needs) and cooperativeness (seeking to meet the other party's needs). The key research questions in this study were how conflict management styles changed as a result of participation in an intense team-based course and whether gender or personality type influenced students' conflict management styles. Students completed a pre-course team formation survey that included prompts on how they would deal with different scenarios representing common team conflicts; students responded to the same prompts again in a project exit survey. Students' responses in these surveys were used to code their preferred approach for dealing with conflicts. Two independent reviewers worked from randomized, anonymous survey data and coded students' responses along the two dimensions of Maddux' model.

The results indicate conflict management style is context dependent (the distribution of responses changed for the different survey prompts). The most commonly used conflict management style was Compromising, in which parties find a middle ground but neither fully achieves their goals. A statistically significant reduction in assertiveness was found between pre- and post-surveys. Statistically significant differences in assertiveness were also noted with a number of Myers-Briggs personality type pairs in the pre-survey. The fact that similar differences were not observed in the post-survey suggests that the project experience has a normalizing effect on conflict management style. Meaningful statistically significant differences in conflict management style based on gender were not observed.
\end{abstract}

Keywords: Conflict management, gender, personality type, Myers-Briggs, teamwork

\section{INTRODUCTION}

The primary questions this study sought to answer was whether students' conflict management styles were related to gender or personality type, and whether conflict management styles changed as a result of significant team experiences.

Teamwork is an integral part of engineering and engineering education. Well-designed group and team projects can help students gain valuable teaming skills, and accrediting bodies require these skills of engineering graduates [1],[2]. Conflict within a team is inevitable. It can arise anytime, as individuals will have differing goals, values, personality traits, or working styles. If mismanaged, conflict can lead to dissatisfaction of the team members and decreased team performance. In the extreme case, the conflict can grow to consume the focus of the team such that little energy remains to be directed towards accomplishing the team's goals. On the other hand, if managed properly, conflict can lead to improved project outcomes, increased team cohesiveness, and increased self-awareness.

Maddux [3] identified five main styles of dealing with conflict based on two dimensions: assertiveness and cooperation. In this context, assertiveness refers to the degree to which an individual seeks to meet their own needs, and cooperation refers to the degree to which they seek to meet other's needs. This leads to five general conflict management styles, as shown in Fig. 1.

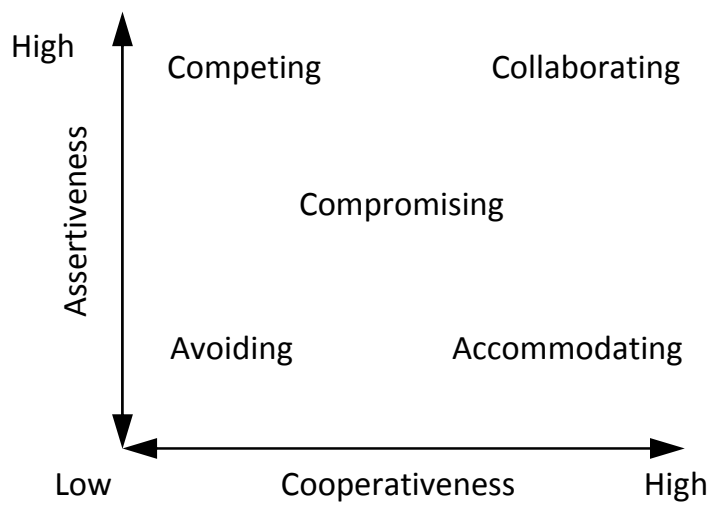

Fig. 1. Maddux' Conflict Management Styles

The key characteristics of each style are,

- Avoiding: the conflict is avoided entirely. An individual sacrifices pursuing their own goals and 
does not help the other party reach their goals either.

- Competing: an individual takes a firm stand to achieve their goals, which may come at the expense of the other party. This style can potentially lead to resentment and hurt feelings with the other party.

- Accommodating: an individual cooperates with the other party to a high degree but does so at their own expense. This may work against the individual achieving their goals.

- Compromising: both parties meet in the middle, but neither one fully achieves their goals.

- Collaborating: both parties work together so that everyone gets what they want. This is the "winwin" case, but it takes the most effort from both parties.

In Section 2 of this paper we provide the details of the settings of this study (i.e., a design course) and in Section 3 we cover the study methods. Results and discussion are included in Section 4, and Section 5 concludes by reflecting on the findings and limitations of this work.

\section{COURSE CONTEXT}

This study was conducted in the Department of Mechanical Engineering at the University of British Columbia (UBC) in a second-year mechanical design course (MECH 223). The course is part of the integrated Mech 2 Program introduced in 2004 [3]. The typical course enrollment is $115-125$ students and two cohorts were considered: Cohort A was from 2013 and Cohort B was from 2015.

The course is delivered using the Team-Based Learning (TBL) approach [5] (details on the coursespecific TBL implementation can be found in [6],[7], and [8]). All students attend a common lecture section (i.e. there are approximately 120 students in the classroom at one time) and they are split into four sections for other activities, such as tutorials, team meetings with a teaching assistant, computer labs, and so on. The MECH 223 course is atypical in several respects: first, it is a full-time course that runs for seven weeks (students do not take other courses at the same time); second, the course is split into two parts (four weeks in January and three weeks in April, each with a separate major design project); and, third, the course is large in scope at seven credits (a typical course at UBC is three credits).

Following recommended practice, teams of six to seven students (20 teams in the course) were instructorformed [9] in order to maximize diversity [10],[11] and to minimize previously established subgroups [5]. Prior to the course, students completed an abbreviated version of the Myers-Briggs Type Indicator (MBTI) online through the TypeFocus tool (http://www.typefocus.com). A mandatory course intake questionnaire then collected each student's MBTI preferences as well as self-reported ability with hand skills, software skills, communication skills, and team skills. The above information was combined with GPA from previous courses to form teams that were heterogeneous across all personality, skill, and GPA criteria. Each team possessed at least two members with each MBTI preference with the exception of the Feeling preference; in most years there were not enough students reporting a preference for Feeling to uniformly distribute them across all teams in light of other team formation constraints. The same project teams were maintained for the course duration, including the January and April sessions.

Lastly, as part of the course, students were introduced to team dynamics and conflict management in multiple ways. Students completed a short textbook reading (8 pages from [12]) at the start of the course. The reading covered the stages of team development, the MBTI and its implications for team work, and Maddux' styles of conflict management. At the start of each project they also participated in a team dynamics workshop (one in January and one in April, as described in [13]). The first workshop focused on understanding the MBTI and developing strategies for working as a team based on the distribution of types on each team. The second workshop focused on debriefing the experiences from the first project and then developing strategies for giving and receiving feedback and managing conflict.

\section{METHODOLOGY}

This study was conducted by analyzing differences between pre- and post-surveys. Pre-surveys were completed as part of a mandatory team formation questionnaire completed before the course and postsurveys were completed at the conclusion of a major course project. For Cohort A, the post-survey was an optional survey completed at the end of the course; for Cohort B, the post-survey was a mandatory team reflection questionnaire completed at the end of the first project in January.

The surveys were administered online. Students responded to prompts asking how they would deal with different scenarios. The scenarios involved common team dysfunctions, as reported by previous students in the course. The instructions given to the students were

"The final questions outline common dysfunctions that appear in project teams. In each case briefly describe how you think you would react if faced with the situation presented. There are no right or wrong responses. Try to be as honest as possible as to how you think you would behave, even if that means you would ignore the issue or 
act in a manner that you might later regret. Your responses will remain anonymous."

The prompts the students responded to were

- How would you deal with someone who forces duties on you without getting your input?

- How would you deal with non-committal teammates? (e.g. teammates who do not take initiative or contribute to team discussions)

- What would you do if people in your group have a "whatever" or "marks aren't important" attitude and you do not agree?

Students responded to each prompt in an open-ended text box. Response rates for students who completed both surveys were $42 \%$ for Cohort A and $74 \%$ for Cohort B.

The responses were anonymized and assigned a unique key. Pre- and post-survey responses were randomly mixed together for each prompt to avoid any potential rater bias. Two graduate students each independently coded all student responses in terms of the perceived assertiveness and the perceived cooperativeness, both on 1 to 5 scales $(1=$ low $)$. In reference to Fig. 1 , the rating scale anchors were as shown in Table 1 .

Table 1. Rating scale anchors

\begin{tabular}{ccc}
\hline \multirow{2}{*}{ Conflict Management Style } & \multicolumn{2}{c}{ Anchors } \\
\cline { 2 - 3 } & Assert. & Coop. \\
\hline Avoiding & 1 & 1 \\
\hline Accommodating & 1 & 5 \\
\hline Compromising & 3 & 3 \\
\hline Competing & 5 & 1 \\
\hline Collaborating & 5 & 5 \\
\hline
\end{tabular}

Even numbers were used for intermediate ratings. The ratings from each coder were included as separate points. Inter-rater agreement was measured separately for each prompt for assertiveness and cooperativeness ratings using Pearson's Correlation Coefficient, $r$, and Cohen's Kappa. Values of $r$ varied from 0.59 to 0.78 , suggesting strong correlation between the two raters, while $\kappa$ varied from 0.17 to 0.36 , suggesting a slight difference in mean ratings between raters. With ratings of 2 to 4 binned in the same group, $\kappa$ improved to 0.48 to 0.58 . The average rater deviation was 0.7 on the 5-point scale.

Statistical comparisons of changes over time, and differences between groups were performed using STATA (StataCorp, College Station, TX). Students that did not complete either the pre- or post-survey were removed from the data set, although students who did complete both surveys but had some responses that could not be rated (either due to ambiguity or brevity) were included.
Mixed linear models were used to assess differences between time points and/or groups (gender, MTBI preferences), with nesting within individuals (repeated measures). Due to the differences in data collection methodology between cohorts, data from the two cohorts was assessed separately for the most part. The two dimensions of assertiveness and cooperativeness were assessed independently.

\section{RESULTS AND DISCUSSION}

Results are presented and discussed below in terms of overall distributions and changes in conflict management style, differences in conflict management style with respect to gender, and differences in conflict management style with respect to personality type.

\subsection{Distribution of Conflict Management Styles}

A comparison of the distribution of conflict management styles for pre- and post-surveys is shown below for both cohorts combined. (Approximate distributions and trends were similar for each cohort.) To bin responses, the ratings from the two evaluators were averaged. Results with assertiveness and cooperativeness ratings greater than 2 and less than 4 (i.e. between 2.5 and 3.5 , inclusive, given the results were the average of two integer ratings) were categorized as Compromising. The remaining responses were coded according to the quadrants of Fig. 1 (see also Table 1).

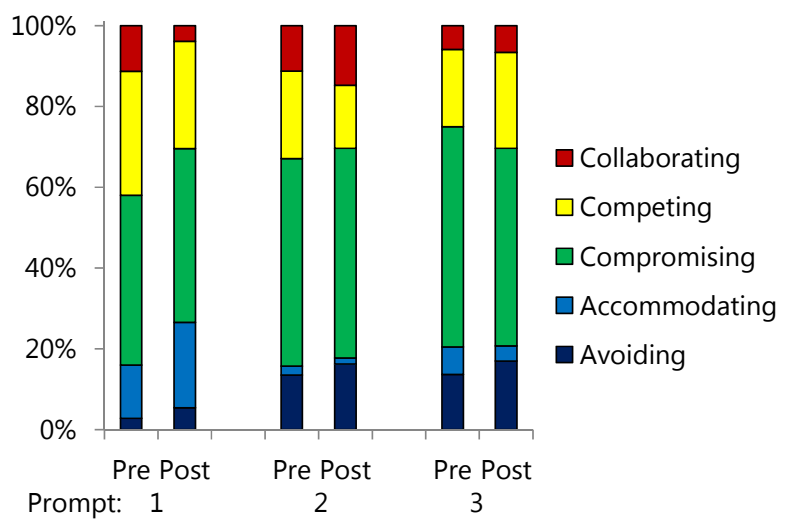

Fig. 2. Distribution of conflict management styles

The above distributions indicate that the most prevalent conflict management style expressed is Compromising. The results also suggest students' preferred conflict management styles are context dependent: they express more accommodating and competing behaviours in Prompt 1 (when someone forces duties on them), and more avoiding and compromising behaviours with Prompts 2 and 3 (with underparticipating or noncommittal teammates). 


\subsection{Changes in Conflict Management Style}

The most notable result from this study was a reduction in average student assertiveness between presurvey and post-survey. The average assertiveness and cooperativeness in pre- and post-surveys (all prompts) are shown graphically in Fig. 3. (The direction of arrow is pre-to-post.) There is a more pronounced reduction in assertiveness compared to cooperativeness for Cohort A, and similar reductions in both assertiveness and cooperativeness for Cohort B.

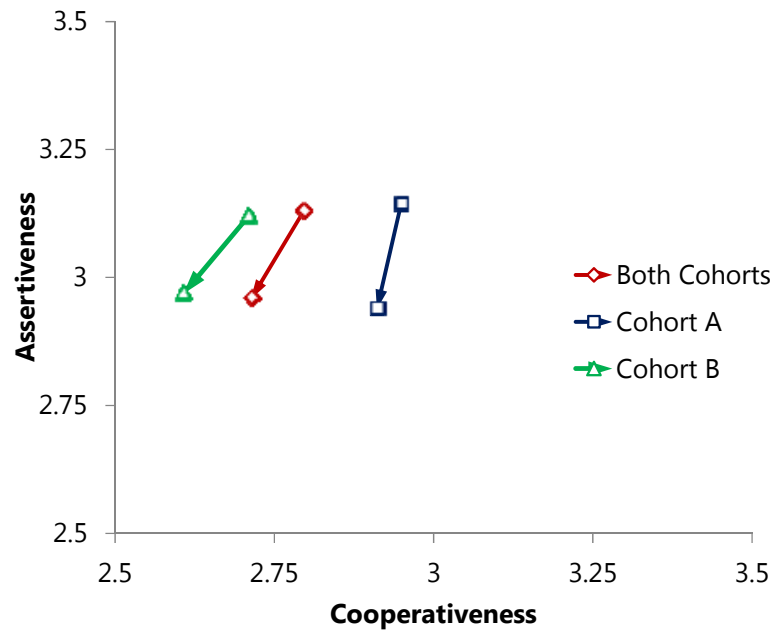

Fig. 3. Pre- to post-survey changes in assertiveness and cooperativeness

The reduction in assertiveness was statistically significant and was observed for both cohorts combined ( 0.17 reduction, $\mathrm{p}<0.001)$ as well as each cohort separately (Cohort A: 0.21 reduction, $\mathrm{p}=0.012$; Cohort $\mathrm{B}$ : 0.15 reduction, $\mathrm{p}=0.008$ ). Full data, post-survey minus pre-survey, is shown in Table 2.

Table 2: Pre-post survey differences

\begin{tabular}{|c|c|c|c|c|c|}
\hline \multirow{2}{*}{ Prompt } & \multirow{2}{*}{ Cohort } & \multicolumn{2}{|c|}{ Assertiveness } & \multicolumn{2}{|c|}{ Cooperativeness } \\
\hline & & $\Delta$ & $p$ & $\Delta$ & $p$ \\
\hline \multirow{3}{*}{ All } & Both & -0.17 & $<0.001$ & -0.08 & 0.09 \\
\hline & A & -0.21 & 0.012 & -0.04 & 0.67 \\
\hline & $\mathrm{B}$ & -0.15 & 0.008 & -0.10 & 0.07 \\
\hline \multirow{2}{*}{1} & $A$ & -0.30 & 0.026 & -0.19 & 0.17 \\
\hline & $B$ & -0.12 & 0.21 & 0.03 & 0.79 \\
\hline \multirow{2}{*}{2} & A & -0.22 & 0.12 & 0.12 & 0.36 \\
\hline & $\mathrm{B}$ & -0.25 & 0.011 & -0.06 & 0.49 \\
\hline \multirow{2}{*}{3} & A & -0.13 & 0.25 & -0.03 & 0.80 \\
\hline & B & -0.08 & 0.44 & -0.28 & 0.002 \\
\hline
\end{tabular}

For all prompts and for both cohorts, average assertiveness rating decreased from pre- to post-survey. The results were statistically significant when considering all prompts, as well as for Prompt 1 with Cohort A and
Prompt 2 with Cohort B. In terms of cooperativeness, there also tended to be a decrease from pre- to postsurvey, although this was statistically significant for only one isolated case (Prompt 3, Cohort B).

\subsection{Conflict Management Style and Gender}

In terms of differences in conflict management style and gender very few statistically significant effects were observed. The observed effects were isolated to specific prompts and were not consistent between the two cohorts, as shown in Table 3 .

Table 3. Statistically Significant changes in conflict management style with respect to gender (male - female)

\begin{tabular}{cccccc}
\hline Cohort & Prompt & Dimension & Survey & $\Delta$ & $p$ \\
\hline A & 1 & Coop. & Post & -0.89 & $\mathbf{0 . 0 3 6}$ \\
\hline B & 3 & Assert. & Pre & 0.40 & $\mathbf{0 . 0 2 0}$
\end{tabular}

The results in isolation suggest males are less cooperative and more assertive; however, considered with all of the results that were not statistically significant, they may simply be type I errors (false positives). Given no effect is observed for the three prompts considered together, the most strongly supported conclusion is that there is no significant gender effect in changes in conflict management style.

\subsection{Conflict Management Style and Personality Type}

Similar to gender, only isolated effects and no clear trends between cohorts were observed in terms of differences involving personality type (see Table 4).

Table 4. Statistically Significant changes in conflict management style with respect to MBTI

\begin{tabular}{|c|c|c|c|c|c|c|}
\hline Coho & rom & imensic & Surve & Domain & $\Delta$ & $p$ \\
\hline & All & Assert. & Pre & $T-F$ & -0.34 & 0.047 \\
\hline A & 2 & Assert. & Pre & $T-F$ & -0.53 & 0.037 \\
\hline & 3 & Coop. & Pre & $J-P$ & 0.52 & 0.013 \\
\hline & All & Assert. & Pre & $J-P$ & 0.17 & 0.047 \\
\hline & 1 & Assert. & Pre & $T-F$ & 0.37 & 0.047 \\
\hline $\mathrm{R}$ & 1 & Assert. & Pre & $I-E$ & -0.49 & $<0.001$ \\
\hline B & 3 & Assert. & Pre & $J-P$ & 0.29 & 0.044 \\
\hline & 1 & Assert. & Post & $I-E$ & -0.34 & 0.048 \\
\hline & 2 & Assert. & Post & $J-P$ & 0.34 & 0.026 \\
\hline
\end{tabular}

Of note from Table 4, with the exception of one case, all statistically significant differences relate to the assertiveness dimension of conflict management. In addition, the majority of differences are observed in the pre-survey. Together, these results suggest that the team 
project experience has a normalizing effect on conflict management style in terms of the degree of assertiveness.

\section{CONCLUSIONS}

In this paper, conflict management style of students in a project-intensive second year mechanical engineering design course was studied through the use of pre- and post-surveys. Responses were categorized using Maddux' framework, which describes conflict management style along two dimensions: assertiveness and cooperativeness. Data from two cohorts was considered. There were five main findings:

- The most prevalent conflict management style expressed appeared to be Compromising (both parties meet in the middle, but neither one fully achieves their goals).

- Conflict management style appeared to be context dependent, as students replied differently to prompts involving a teammate forcing duties upon them versus a teammate who under-participated.

- A statistically significant reduction in assertiveness between pre- and post-surveys was noted for both cohorts.

- There did not appear to be any meaningful statistically significant differences in conflict management style between male and female students. (Two isolated statistically significant effects were observed, but these were for different surveys, different prompts, different conflict management dimensions, and different cohorts.)

- Statistically significant differences in conflict management style with respect to personality type (described by the MBTI) were almost exclusively observed with respect to the assertiveness dimension and with the pre-surveys. This suggests the team experience has a normalizing effect on the degree of assertiveness in dealing with conflict.

Overall, the results suggest that differences in conflict management style exist, but that these are dynamic and are not overly large.

\section{LIMITATIONS}

While Cohort A and B were treated differently in the analysis, the fact that post-surveys for Cohort A were optional may have attracted a different type of student and may have skewed those results. In addition, as the postsurveys were completed at the completion of a major project, it is unclear whether any measured changes represent a permanent difference in student behaviour or attitude, or if instead they are capturing students at a different emotional state (due to the completion of a stressful demanding team project). As with any study completed in one course at one institution, care should be taken before attempting to generalize any of the findings.

In terms of future work, the impact of the team dynamics workshops conducted at the start of each project has not been considered. The second workshop (at the start of Project 2) focuses on communication, giving and receiving feedback, and conflict management, but this was only taken by the students in Cohort A. This may have influenced the results of Cohort A, but it is difficult to separate this effect from other effects due to the Cohort A post-survey being optional. In addition, differences due to the second project experience likely had an effect on Cohort A. If this study is continued, a future cohort will likely receive a pre-survey, a mid-course survey (between the two projects), and Project 2 exit survey, and a followup survey several months after students have left the course. This would help to separate the transient effects from lasting changes.

\section{References}

[1] CEAB, Accreditation Criteria and Procedures: Canadian Engineering Accreditation Board (CEAB), 2012, 114 pp. Available as of May 3, 2013 from: http://www.

engineerscanada.ca/files/w_Accreditation_Criteria_Proc edures_2012.pdf

[2] ABET, Criteria for Accrediting Engineering Programs, Baltimore, MD: Accreditation Board for Engineering and Technology (ABET), 2012, 26 pp. Available as of May 3, 2013 from: http://www.abet.org/uploadedFiles/Accreditation/ Accreditation_Step_by_Step/Accreditation_Documents/ Current/2013_-_2014/eac-criteria-2013-2014.pdf

[3] Maddux, R., "Team Building: An Exercise in Leadership,” Kogan Page Publishers, 1994.

[4] Ostafichuk, P.M., Croft, E.A., Green, S.I., Schajer, G.S., and S.N. Rogak, "Analysis of Mech 2: An AwardWinning Second Year Mechanical Engineering Curriculum," in Proc. of EE2008 (Loughborough, UK, 14-16 July, 2008), 12 pp., 2008.

[5] Michaelsen, L., Sweet, M., and D. Parmelee, TeamBased Learning: Small Group Learning's Next Big Step. New Directions for Teaching and Learning, JosseyBass, San Francisco, 129 pp. \{ISBN: 978-0470462126\}

[6] Hodgson, A.J. and P.M. Ostafichuk, "Team-Based Learning in the Design Modules of a New, Integrated, 2nd Year Curriculum at UBC," in Proc. CDEN 2005 (Kananaskis, AB, 17-20 July, 2005), 9 pp., 2005.

[7] Hodgson, A.J. and P.M. Ostafichuk, "Designing Extended Assignments for Team-Based Learning Modules," in Proc. CDEN 2006 (Toronto, ON, 24-26 July 2006), 10 pp., 2006. 
[8] Ostafichuk, P.M. and A.J. Hodgson, "Standing on Our Heads: How Teaching Engineering Design Looks Different from a Team-Based Learning Perspective", in Proc. Team-Based Learning Conference 2007 (Vancouver, BC, 31 May - 1 June, 2007), 36 pp., 2007.

[9] Brickell, J., Porter, A., Reynolds, M., and R. Cosgrove, "Assigning Students to Groups for Engineering Design Projects: A Comparison of Five Methods," Journal of Engineering Education, Vol. 83, Issue 3, pp. 259-62, July 1994.

[10] Feichtner, S., and E. Davis, "Why Some Groups Fail: A Survey of Students' Experiences with Learning Groups," The Organizational Behaviour Teaching Review, 9 (4), pp. 58-73, 1984.
[11] Weimer, M., "Why Groups Fail: Student Answers," The Teaching Professor, Vol. 5, No. 9, November 1991.

[12] Ostafichuk, P.M., Hodgson, A.J. and M. Fengler, The Engineering Design Process: An Introduction for Mechanical Engineers. Vancouver: Ostafichuk, 2013 ( $2^{\text {nd }}$ ed.), 434 pp., \{ISBN 978-0-9920587-2-2\}

[13] Ostafichuk, P.M., Hodgson, A.J., Bartek, S. and C. Naylor, "Teaching Team Dynamics: Experiences in Second Year Mechanical Engineering Design", in Proc. CDIO Conference (Montreal, QC, 14-17 June, 2010), 10 pp., 2010.

[14] Ostafichuk, P.M. and C. Naylor, "The Influence of Personality Type on Teamwork in Engineering Education," in Proc. 2013 CEEA Conf. (Montreal, June 17-20, 2013), 7 pp., 2013. 